\title{
Investigating the Effects of a (Non-) Professional Interpreting Service in Healthcare
}

\author{
Harold M. Lesch \\ Department of Afrikaans and Dutch \\ Stellenbosch University \\ Private Bag X1 7602 Matieland
}

\begin{abstract}
Much of our societal interaction is sustained and enriched by communication across linguistic borders between fellow citizens, which is not necessarily due to the influx of people from less affluent countries. In contrast to the often figurative gesture of an interpreting service, interpreting does in fact take place at the coalface of everyday activities where a linguistic impasse occurs. Even though we subscribe to the notion of parity and esteem of our languages, the reality is, however, that our daily life is saturated by inconsistent power inequality and redress. Interpreting in such instances cannot be "a neutral and symmetrical exchange between two equal cultural forces" (Mezei et al., 2014:13). Interpreters - whether trained, poorly trained or untrained - have crucial and often unrecognised and unforeseen effects. Consequently, this article surpasses official multilingualism, the movement between the languages concerned and the analysis of linguistic transfer. Instead, the focus is on the social effects of interpreting. The practical aspects of interpreting and the examination of the societal context of interpreting are the central points in this article. A language barrier between patients and healthcare service providers is a major stumbling block for the provision of quality care to a culturally diverse society. Such an obstacle correlates negatively with patient satisfaction and studies have showed that patients experiencing language difficulties are less likely to return for follow-up consultations and also less likely to comply with prescriptions (Schlemmer, 2005:4). Against this backdrop, this article will take as its methodology revisiting instances of healthcare interpreting services. These instances will be contextualised and framed in terms of the society in which they occur. This will be done with reference to the event and effect (see Chesterman, 1998). The ultimate goal is to determine and deliberate on the event and effect in terms of the practical aspects of interpreting and the examination of the societal context of interpreting.
\end{abstract}

Keywords: interpreting, effect, event, social aspects, healthcare

\section{Introduction}

Social interaction in South African is often sustained and enriched by communication across linguistic borders between fellow citizens which are not necessarily due to the influx of people from less affluent countries. In contrast to the often-symbolic dimension of an interpreting service, interpreting does in fact take place in the coalface of everyday activities where a linguistic impasse occurs. Even though we subscribe to the notion of parity and esteem of our languages, the reality is, however, that our daily life is saturated by power inequality and redress. Interpreting in such instances cannot be "a neutral and symmetrical exchange between two equal cultural forces" (Mezei et al., 2014:13). A non-professional interpreting service ${ }^{1}$ - provided by inexperienced, untrained or poorly trained interpreters - has crucial and often unrecognised and unforeseen consequences. Accordingly, this article focuses not so much on multilingualism, the movement between the languages concerned and the analysis of linguistic transfer, but rather on the social effects of the interpreting service itself. The practical aspects of interpreting and the examination of the societal context of interpreting are the focal points.

My focus in this paper is on the effects that are the result of an action. It thus makes sense that I should also refer to the causes or origins of the action. Even though there is a dialectical relationship between causes and effects, the action to address the causes can result in unintended social behaviour, meaning that there is not necessarily a positive relationship between the two. This is also evident in the case of interpreting as will be deduced from the existing research that is revisited and reflected upon. Causality (that is cause and effect) is not a new notion in translation, as it entered translation studies indirectly in several ways (Chesterman, 2000:19; see also Mezie et al., 2014). Nida's (1964) notion of dynamic equivalence includes the idea of attaining the same effect. Skopos theory of Nord (2005) in turn foregrounds the cause or intention and skopos itself is defined as "intended effect". Researchers of the polysystem approach and the "cultural turn" use concepts such as norms in both the source and target cultures to explain translation causes and effects. In addition, Toury's (1995) proposed laws of interference and standardization aim to take us beyond description to explanation.

${ }^{1}$ The emphasis is on the service and the nonprofessional nature there of which should be seen within the context of Antonini et al. (2017:4-8). 
The tradition of translation assessment and criticism can also be viewed in terms of translation effects ${ }^{2}$. A translation critique is the reflection of an effect that a given translation has in the mind of the reviewer or client. One can further add that the "[p]rescriptive statements about what translators should or should not do are implicit hypotheses of effect: they predict good/bad effects of particular translational choices" (Chesterman, 2000:19). In essence, reception studies also review the translation effects. In the recent past, however, limited inroads have been made with the training of healthcare interpreters. It is noteworthy that in South Africa communication problems are not only encountered with immigrants but also with fellow South Africans.

South Africa has 11 official languages and is essentially a multilingual and multicultural country. This leads to a situation where fellow South Africans themselves are not able to understand one another effectively and it is not merely a matter of foreign citizens not being understood. The official languages in the Western Cape - where the data was collected - are Afrikaans, English and isiXhosa. The Western Cape has a total population of 5822734 of which the largest linguistic group of the residents is comprised of Afrikaans speakers, i.e., $49.6 \%$ of all Western Cape residents. IsiXhosa is the language spoken by the second-largest proportion of the Western Cape population, i.e. $24.7 \%$. English is spoken by $20.2 \%$ of the Western Cape population (Census, 2011).

At the turn of the century, Cole et al.(2003:28-29) confirmed that there were no official interpreters in healthcare (Western Cape) and that the biggest need was for interpreting between isiXhosa speakers and non-isiXhosa health workers. At the time of their survey, the main source of interpreters was nurses, nursing assistants, auxiliary staff and community volunteers. At the time of their survey, interpreting was entirely informal and it was mainly the nursing staff that were being used and their services were not officially recognised.

In the recent past, limited progress has been made regarding the availability of healthcare interpreters in these hospitals but one can argue that it is still a non-professional interpreting service that is being offered.Within the African context, the divide between the first and second economy is obvious, where in the second, i.e. informal economy, non-professional interpreters and translators are the norm in public spaces and it has become increasingly clear that such circumstances are likely to prevail for some time yet. The designation "non-professional" in itself is rather blurred in that it is often used as equivalent to "ad hoc", "unpaid", "volunteer", "informal" and "limitedly trained" in translation or interpreting (NPIT4:2018).

We do not have a history of formal healthcare interpreting in the country and the in-house rules that applied to the interpreters are imprecise if there are any. Moreover, healthcare interpreters at these institutions are not obliged to be accredited or at least be registered at the South African Translators Institute (SATI) as the professional body for interpreters and translators in the country. Resultantly, non-professional interpreters are often the norm in healthcare interpreting.

Against this backdrop, this article will take as its methodology revisiting and reflecting on previously conducted research on healthcare interpreting. These instances will be contextualised and framed within the healthcare community. This will be done with reference to the event and effect (see Chesterman, 1998). The ultimate goal is to determine and deliberate on the effects of the interpreting service within healthcare. Existing empirical data has been mined with the focus on the theoretical notion of effects. The knowledge that is gleaned through this investigation surpasses the notion of mere multilingualism, the movement between the languages concerned and the analysis of linguistic transfer. The discussion will rather in all likelihood contribute to improving the service and feed into curriculum development for interpreter training.

The article is structured as follows: first a literature review will be provided; then relevant existing research will be discussed; and, finally, the effects of the interpreting service will be considered in terms of the literature.

\section{Literature review}

The effects of translation and interpreting extend far beyond what is usually assigned to translation by official multilingualism and the subsequent traffic between the official languages in South Africa. Translations (including interpreting) as phenomena has both causes and effects (Chesterman, 1998:213-219; see also Mezei et al., 2014). However, the causes, or the causal model, are not the focus of this article. Instead, the focus is on the effects of the interpreting service.

As Mezei et al.(2014) set out to present the translation practices in Canada and refer among others in their publication to the diversity of interactions in the Canadian culture, including between immigrant and First Nation languages, and the unequal terrain upon which these interactions occur.

\footnotetext{
${ }^{2}$ Even though this article focuses on interpreting, it draws primarily on Chesterman's (2000) and theoretical constructs concerning translation. I am of the opinion that these constructs and Chesterman's claims also holds within the context of interpreting; this is also the rational of Mezei et al. (2014). Consequently, translation effects will thus encompass interpreting effects within the context of this paper.
} 
They are of the opinion that "translation can have crucial and often unacknowledged effects" (Mezei et al., 2014:4) and they examine the spread of the translation effects in Canada in their edited publication. Likewise, South Africa is a diverse unequal multilingual society, and a similar investigation could be duplicated here or anywhere else where interpreting and translation are pursued.

Even though Chesterman (1998:202) refers to translation (see footnote 1), one can also juxtapose his viewpoint with interpreting when he states that we spend much time and energy improving our conceptual tools but less time actually doing anything with these tools. In accordance with this view, Berglund states in 1990 already that we focus so much on theory that it becomes harder for the theory to appear relevant to the professional translator and to translation practice. Just before the turn of the millennium, there was the argument that practicing professional interpreters would find it more useful to be informed about the conceptions and expectations of the clients and about the attitude of the general public to translation or to interpreting services than about scholarly arguments (Chesterman, 1998:202). For the sake of not being misunderstood, it is important to note that I do not at all disregard the importance of theory for translation or interpreting practice. Following this logic, more emphasis should be placed on the dialectical relationship between theory and practice to develop a relevant service for the parties involved. The disadvantage, however, is that if conceptual analysis becomes an end rather than a means, it makes it more difficult to adopt a standard empirical methodology.

Translation theory is also interested in translation texts as causes, as translators, and interpreters, are also agents of change. They are not only passive receivers of casual impulses. Instead, there is a close link between translation and social movements in that social movements rely on translation (Mezie et al., 2014). The same applies to the commissioners of the translation or interpreting service. The decisions that translators and interpreters make, and ultimately the translations they produce, have effects on the reader of the target text or the target text listeners of the interpreted text. Their decisions also have effects on intercultural relations in a more general sense.

According to Chesterman (1998:219), the study of translation effects is "currently a messy field, mixed up with beliefs about 'sameness of effect', evaluative reactions of various kinds, and prescriptive statements". One should draw a distinction between the mere existence of a translation or interpreting service, the effect of such a service and the manner in which a given text is translated or interpreted. The emphasis in this study falls on the service that is being provided.

It is difficult to define effect in itself and, as such, it is even more difficult to measure it. An initial definition as a starting point might be: "an effect is a change of mental state (emotional, cognitive, etc.) in the reader" (Chesterman, 1998:219). This is a proximate effect, which is a mental effect, and it is not directly observable as is the proximate cause, which is also mental. The secondary effects can be defined in terms of the subsequent actions on the part of the reader or group of readers (listeners or group of listeners of the interpreting), i.e. actions that are observable (e.g. using their medication and attending follow-up visits to the hospital). These are called behavioural effects. Some of the secondary effects are less easily observed (e.g. effects due to an increase on knowledge or an aesthetic or artistic experience) (Chesterman, 1998:219).

Tertiary effects might be observable in the target culture as a whole and also in the intercultural relations between the source and the target cultures. The target language norms might be affected. Under the influence of the new incoming translations, literary genres might shift. People's eating or drinking habits may start to change, mass conversions to another religion may occur and war might break out (Chesterman, 1998:219-220). In this article's case, the interpreting genre might shift, people's healthcare habits might change, language use, e.g. favouring multilingualism, might change and attitude toward language policy might change. Consequently, studies can examine the secondary tertiary effects of particular translation and interpreting services as well as the causes of the effects. In other cases, hypotheses about the effects of particular translation types or methods can be tested and perhaps falsified.

At the basis of the effects lies the notion of causal model of translation studies that can be read as (Chesterman, 2000:18-19):

If X (in the source text) occurs, $Y$ will follow (in the target text).

If we adopt a causal model to translation, the effects can be linked logically to the causes. In its simplest form, any causal model can be represented as:

cause $==>$ Effect

where

“=>" signifies causes or produces;

thus,

causes $=>$ translations $=>$ effects.

In practice, a multilingual language policy serves as the cause or root for a dedicated interpreting service in the case of multicultural contact in public spaces, aiming to produce positive effects, i.e. bridging the communication gap, 
and ultimately, improved healthcare. However, the effects can be unaligned, and thus be unintended, and can result in unforeseeable situations - positive or negative - not only of the target text but also of the mere fact that an interpreting service is available. There are accordingly various levels of causation that should be considered: cognitive (the translation act); situational (the translation event); and socio-cultural (e.g. patient behaviour).

Chesterman (1998:220-222) suggests three general laws of effects that can be derived:

1. The law of heterogeneous effect: translations (or interpreting) tend to have different effects on different people.

People do not react identically to the same translation. This is due to the fact that people are socially different and have different cognitive backgrounds and life experiences and different aesthetic values. Consequently, none of us react in the same way to a given translation or interpreting text or service.

2. The law of changing effect: even with respect to a single reader (or listener), the effect of an interpreting text changes over time.

It is obvious that readers develop and mature. Their sociocultural environment changes and so does their language. The result is that we observe delayed effects. Likewise, cultures and languages change over time and so do the interpreting effects (see for instance oral educational interpreting in the tertiary setting in South Africa).

3. The law of multiple effects: even with respect to a single reader or listener at a given time, a translated or interpreted text tends to have more than a single effect.

Even if one can pinpoint the main effect, there are usually also side effects that resulting from the text or service.

\section{Parameters of effect}

Apart from the laws, translation effects can be classified along various parameters. In the process of doing such classifications, one should move away from the level of the individual reader or listener and also generalize upwards from detailed differences between the effects. The classes of the type of effects are very irregular and can be developed further (Chesterman, 1998:222). The following four parameters can be identified:

\section{Intended vs unintended effect}

Intended effect is that which the translator (interpreter) and/or the client and/or original writer (speaker) intends. A subdivision would then be the (un)intended effect on intended vs unintended readers. Pym (1992) refers to excluded, participative and observational receivers. Where the excluded receiver refers to a reader or listener who is unable to participate in the message of a text, because it is not addressed to him (Shuttleworth and Cowie, 1997:32); the participative receiver is a reader or listener to whom the text is explicitly addressed (Shuttleworth and Cowie, 1997:122); and an observational receiver is a reader or listener who is unable to understand the message of the text even though they are not specifically addressed in it (Shuttleworth and Cowie, 1997:115). The intended effect on its intended participative readers or listeners is often paraphrased by the skopos, but the intended effect is at times more slippery than the skopos. The reactions of the reader or listener related to this distinction may be illustrated by questions such as: Is this supposed to be funny? Is this meant for patients? What did the interpreter mean with this?

4. De re (i.e. about the thing, the message) vs de dicto (i.e. about the form of the message, e.g. readability or audibility) effect of the translation

The translation critic usually focuses on both the de re and the de dicto effects. The ordinary reader or listener usually disregards the de dicto effects unless their attention is specifically drawn to it (Chesterman, 1998:223). Remarks such as"X does not sound right", "It reads like a translation" and "It sounds old-fashioned" refer to the de dicto effects.

\section{Desirable to undesirable effect}

Desirable does not necessarily coincide with intended effect. Questions arising in this regard include: To whom is it desirable? Is it desirable to the same party as the one that is doing the intending/planning or a different one? Is it desirable to, for example, the translator or interpreter, client or reader or listener? The client can even reject the translation or could complain about the interpreting service if they feel that the effect is undesirable.

6. Sameness or similarity of meaning: effects that are more or less similar to those of the source text on the source text readers or listeners vs those that are not similar or less similar.

Some of the reaction in this regard can also be evaluative while others are purely descriptive.

One should also add the quantitative aspect to the four parameters, that is, the degree or the intensity of the effect. However, to measure the intensity remains a problem - even more so if the effects are mental. 
In his article, Clifford (2014:416-429) focuses on interpreting effects from the viewpoint of the legislative framework and the end-users within the healthcare system in Canada. He states that to call upon family to interpret is to fail to understand the importance of interpreting quality and that the lack of quality will be a direct cause of negative patient outcomes (Clifford, 2014:418). Likewise, the data to my disposal for this article is taken from the healthcare setting from the multilingual South African context and I will reflect on it in terms of Chesterman's terminological framework.

\section{Methodology}

The methodology involved is to revisit existing empirical data from previous research ${ }^{3}$ that was undertaken by the author in terms of the theoretical framework provided above. Two phases of data collection were involved. The first phase aimed at compiling a profile of the relevant interpreters, whereas the second phase entailed completing a comprehension test, i.e. an exercise to ascertain whether the interpreters understood the test that they were supposed to explain to the patient.

The existing data that were initially collected took on the form of a small-scale survey that involved the three public hospitals in the Western Cape, South Africa, namely Tygerberg Hospital (TBH) Groote Schuur Hospital (GSH) and Red Cross Hospital (RXH).

\section{The Context}

Tygerberg Hospital is linked to Stellenbosch University as a tertiary-level medical institution. The hospital was opened in 1976 and employs 1938 nurses and 577 doctors. Each year more than 107215 patients are admitted to TBH, while more than 492670 patients visit Tygerberg Hospital annually. ${ }^{4}$ The staff mainly has Afrikaans as their mother tongue with a small proportion with English as their mother tongue. The patients are also mainly Afrikaans speakers with again only a small proportion with English as their mother tongue. IsiXhosa is the predominant language among indigenous African language 5 patients (Saulse, 2009: 24).

The RXH is the only child health institution in South Africa and is located near Cape Town. It treated approximately 20787 admitted patients in 2018 and 121 518outpatients in 2018. ${ }^{6}$ This hospital is linked academically to the Stellenbosch University, the University of Cape Town, and the Faculty of Dentistry of the University of the Western Cape. The staff use both English and Afrikaans in equal proportions, while the language among patients is very diverse with English, Afrikaans and isiXhosa being used on an almost equal basis (Saulse, 2009:24).

Groote Schuur Hospital, linked to the University of Cape Town, is situated in Observatory, Cape Town. This is mainly an English-speaking area. In 2017, GSH had a total number of 1435 nurses and 532 doctors with 49953 patients admitted and 356062 outpatients visiting the hospital. It is estimated that GSH staff members speak English and Afrikaans in equal proportions and a small proportion of indigenous African languages is evident. Among patients, there is also a shared dominance between Afrikaans and English and a large proportion of indigenous African or other languages. ${ }^{7}$

The statement by Feinauer and Lesch (2013: 216-217) regarding the profile of typical state hospital patients in the Western Cape is accordingly still relevant:

[T] hey are mostly lay people from a low socio-economic level who are language impoverished, have low or no level of schooling, lack communication skills, sometimes do not use the standard varieties of Afrikaans, English, or isiXhosa; they are economically deprived; they have low concentration levels; they are ill, are intimidated by the unfamiliar environment, and are without any medical knowledge.

\section{Reflecting on the data}

Against this theoretical backdrop, I revisited previously conducted research (Feinauer and Lesch, 2013) in healthcare interpreting in the Western Cape in which I was to a greater or lesser extent involved either as supervisor

\footnotetext{
${ }^{3}$ Empirical data involved include Feinauer and Lesch (2013) and Lesch and Saulse (2014). For both these studies, the necessary ethical clearance was obtained from the relevant bodies.

${ }_{5}^{4}$ https://www.westerncape.gov.za/assets/departments/health/tygerberg_hospital_information_pamphlet_-2016.pdf

5 An African language is a language spoken on and has its roots in the African continent. Indigenous African language include Sepedi, Sesotho, Setswana, siSwati, Tshivenda, Xitsonga, isiNdebele, isiXhosa and isiZulu. As Afrikaans, one of the official languages in South Africa derived from Dutch it is seen as an African language but not an indigenous African language but from European origin.

${ }^{6}$ https://www.childrenshospitaltrust.org.za/wp-content/uploads/2019/07/The-Childrens-Hospital-Trust-Annual-Report2018.pdf)

${ }^{7}$ https://www.gshfb.co.za/wp-content/uploads/2017/11/fast-facts-2017.pdf

18
} 
of a master's thesis or as researcher doing the investigation and collecting the data ${ }^{8}$. One should state at this point that, according to Chesterman (1998:225-226), it is impossible to investigate what effects a given translation (interpreting) service or text has on every reader or listener, not even on every intended reader or listener. Consequently, one has to use samples and this in itself gives rise to serious problems: how does one know that the response of the sample manifesting the reactions are typical and intended receivers? If they are not typical, how can one generalize from one's observations about them? On what grounds can one take the reactions of these kinds of people to be typical? Do they even think of themselves as typical readers or listeners? Is the reaction a general reaction to observational receivers in healthcare?

The healthcare sector in the Western Cape is characterised by primarily Afrikaans- and English-speaking doctors, or medical practitioners in general, who do not understand isiXhosa-speaking patients. In order to bridge this language gap, ad hoc interpreting (i.e. the interpreter received no or very limited training; see also Antonini et al. (2017:4-8) services are employed. These interpreting services are often rendered by family members of a patient, nurses or at times even by porters or cleaners.

Healthcare interpreting has the following main objective, namely to empower patients and to improve healthcare service delivery (Lesch and Saulse, 2014). This can be stated as the main intended positive effect for making an interpreting service available. However, as a result of the fact that the aforementioned ad hoc interpreters lack training in interpreting methodology and practice, they often tend to distort communication, and this impacts negatively on the quality of the healthcare services that are being delivered (see Clifford 2014:418). This consequent lack of quality in healthcare can be directly related to the quality of the interpreted product that the interpreter renders. In short, apart from the main intended effect of improved healthcare, the interpreting service unfortunately also has unintended effects such as non-professional, ad hoc interpreters being used. This situation affects the service as a whole as those interpreters do not possess the necessary professional status. The unintended effects further include (Lesch and Saulse, 2014:14-15):

$\checkmark$ Unorganised interpreting practice within the hospitals occurred;

$\checkmark$ The visibility of the interpreters was lacking (see also Clifford 2014 in this regard). At some hospitals, few staff members at the reception desks and in the clinics and wards were aware of the presence of available interpreters. This resulted in only a few patients making use of them;

$\checkmark$ Patients were of the opinion that interpreters were always available when they needed them;

$\checkmark$ A frequent need to wait and reschedule interviews emerged as interpreters were unavailable;

$\checkmark$ Medical practitioners were not told how to use interpreters;

$\checkmark$ The interpreter sometimes nods off during sessions;

$\checkmark$ The waiting period when the interpreter is busy somewhere else emerged as a challenge; and

$\checkmark \quad$ A shortage of staff, i.e. not enough interpreters, occurred.

Lesch and Saulse (2014) also confirm that ad hoc interpreters lack training in interpreting methodology, and they tend to distort communication, which impacts negatively on the quality of the healthcare that the patient receives or on informed consent as incorrect information is transferred. However, the effect of the presence of the interpreter is still perceived as positive by the patients. The consequent lack of quality in healthcare can therefore be directly related to the quality of the interpreting service as there is a dialectical relationship between effective communication and the healthcare service provided. If this is not the case, it can result in veterinary healthcare. It was revealed that due to an interpreter's lack of knowledge or terminology, and/or the lack of sufficient knowledge of the target language, some parts of the message from the medical practitioner to the patient were distorted and the response that the medical practitioner received was not the response required. It could not be determined whether this distortion was due to a lack of knowledge regarding terminology or because of a lack of knowledge of the language. The following excerpt from Lesch and Saulse (2014) confirms this:

$\begin{array}{lll}\text { Patient } & : & \begin{array}{l}\text { Yababhetele ngoku laa nto yokujikeleza kwengqondo. } \\ \text { (It is better now the condition of feeling dizzy.) }\end{array} \\ \text { Interpreter } & : & \text { The nauseous is much more better now. } \\ \text { Doctor } & : & \text { Nauseous? } \\ \text { Interpreter } & : & \text { Yes. } \\ \text { Doctor } & : & \text { Was she vomiting before? } \\ \text { Interpreter } & : & \begin{array}{l}\text { Ubugabha ngaphambili? } \\ \text { (Were you vomiting before?) }\end{array} \\ \text { Patient } & : & \begin{array}{l}\text { Bendingagabhi bekujikeleza ingqondo. } \\ \text { (I was not vomiting but feeling dizzy.) }\end{array}\end{array}$

\footnotetext{
${ }^{8}$ Supervisor for Saulse (2010) and co-author, Feinauer and Lesch (2013); Lesch and Saulse (2014)
} 


$\begin{array}{lll}\text { Interpreter } & : & \text { She says she was not vomiting but err ... err ... } \\ \text { Doctor } & : & \text { Are you saying nausea or dizziness which one is it? } \\ \text { Interpreter } & : & \text { Dizziness. } \\ \text { Doctor } & : & \text { Not nausea? } \\ \text { Interpreter } & : & \text { Not nausea, yes. }\end{array}$

This example illustrates that the interpreter either did not know the English equivalent ("dizzy") for the isiXhosa word or she could not find the English equivalent "dizzy/dizziness" immediately. Despite this, the interpreter did not once request the patient or doctor either to elaborate on the explanation or even to have the word repeated that she was looking for. She probably simply used the word with the closest association ("nausea"), which in this case was not correct. It was only when the patient repeated that she had experienced dizziness that the interpreter realised her faux pas and it became evident that she either did not know the word or that she had completely forgotten it. This faux pas occurred only on a lexical level, as the researcher assumed that the interpreter understood what the patient was referring to, i.e. knew the concept, but could not access the correct term.

The patients seemed to be overly grateful to have someone who was able to bridge the communication gap between themselves and the doctor when there was someone available who could speak on their behalf. Therefore, anyone able to facilitate communication was seen as an interpreter, despite the fact that such interpreters may have deliver an interpreting service of poor quality.

\section{Unrealistic expectations as an unintended effect}

One unintended effect should be considered in more detail. Healthcare professionals sometimes have expectations that interpreters cannot meet. In a study entitled "Health workers: idealistic expectations versus interpreters' competence" conducted by (Feinauer and Lesch, 2013), interpreters were expected to declare in writing that they assisted the medical investigator to explain the information in consent forms for parents of paediatric burns patients and volunteers on antiretroviral therapy. The interpreters also had to declare that the patients fully understand the content of the relevant document and all their questions were satisfactorily answered. The investigation, however, shows that the interpreters did not fully understand the information that they had to explain. None of the interpreters interviewed wanted to sign the agreement certifying that they explained the information of the trial in the patient's mother tongue and that the patient understood it. In this study, it was discovered that the interpreters had to take primary responsibility for conveying the message. Taking the level of education of the interpreters into account, it seems impossible for them to explain the medical procedures so that the patients can make an informed decision. They are thus set up for failure when they are confronted with this task and these documents. The conflict between what is expected of these interpreters and the reality of their position is spelled out.

The obvious effect of making interpreters, whether unqualified or poorly qualified, available in healthcare is to assist with better service delivery, especially if there is a communication impasse. However, it also results in unintended effects of which one is to shift the responsibility from the healthcare professional to the interpreter. This reveals an idealistic expectation that healthcare professionals have of interpreters' competence (Feinauer and Lesch, 2013). One can stipulate this as an unintended and undesirable effect of the interpreting service.

To contextualise the unintended effect one should refer to the empirical data collected. Two phases of data collection were involved. Both were done during one consultation with the interpreters. The first phase aimed at compiling a profile of the relevant interpreters, whereas the second phase entailed completing a comprehension test, i.e. an exercise, to ascertain whether the interpreters understood a written text that they were given by a medical practitioner and that they were supposed to explain.

\section{Profile of interpreters}

The researcher visited the interpreters of the TBH and RXH and participants were asked to complete questionnaires concerning their training, background and comprehension of a translated text. At $\mathrm{TBH}$, only one interpreter was found and at RXH only two were found. Therefore, the GSH was visited where another three interpreters were interviewed, although the informed consent forms were not meant for this hospital. The GSH has a similar profile to that of TBH. The results of the survey are listed in table 1. As English is the pivot, it was used as the language in which the researcher communicated with the interpreters and it was also used the questionnaires.

Regarding the languages offered, at TBH and $\mathrm{RXH}$, no interpreters were found for Afrikaans, whilst in both hospitals Afrikaans was either the most spoken language or used on an equal basis with English and isiXhosa. All six interpreters are mother tongue speakers of isiXhosa with English as their second language.

At RXH, Sesotho and isiZulu are offered as third languages and at GSH two of the interpreters offer Afrikaans as their third language. 
Regarding the interpreters' qualifications, none has a tertiary education and not all have even completed their secondary education. Regarding their training as interpreters and the period that they were interpreting, the interpreter at TBH had no training, but she was a nursing ancillary, who later just moved into an interpreting "position". She has been doing this for the past eight months on a freelance basis at TBH as she has some knowledge of the languages involved.

The two interpreters at RXH have been performing interpreting duties for the past seven years. They are full-time interpreters and had training in interpreting for two years on an ad hoc basis from anon-governmental organisation, namely the National Language Project (NLP). Apart from language and interpreting skills, they also had some training in counselling. They presented themselves in a very professional manner.

The three interpreters at GSH had been doing interpreting in this hospital for the past two years, but were doing interpreting on an ad hoc basis at the hospital for at least ten years before that, even though their job title was that of "cleaner". When they were appointed as interpreters, they underwent some basic relevant non-accredited training for six weeks.

Table1: Interpreters consulted

\begin{tabular}{|c|c|c|c|c|c|c|}
\hline Hospital & $\begin{array}{l}\text { Number of } \\
\text { interpreters }\end{array}$ & Gender & Age & Qualifications & Languages & $\begin{array}{l}\text { Interpreter } \\
\text { training }\end{array}$ \\
\hline $\mathrm{TBH}$ & 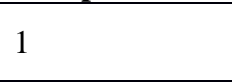 & Female & 33 & $\begin{array}{l}\text { Matric }^{9} \\
\text { (Nursing ancillary) }\end{array}$ & $\begin{array}{l}\text { English, } \\
\text { isiXhosa }\end{array}$ & None \\
\hline $\mathrm{RXH}$ & 2 & Female & $\begin{array}{l}35 \\
53\end{array}$ & $\begin{array}{l}\text { Matric } \\
\text { Post-matric studies } \\
\text { (Adult basic education; } \\
\text { Ancillary social work) }\end{array}$ & $\begin{array}{l}\text { English, } \\
\text { isiXhosa, } \\
\text { isiZulu } \\
\text { English, } \\
\text { isiXhosa, } \\
\text { Sesotho }\end{array}$ & $\begin{array}{l}\text { Two-year } \\
\text { relevant } \\
\text { training }\end{array}$ \\
\hline GSH & 3 & $\begin{array}{l}\text { Male } \\
\text { Female } \\
(2)\end{array}$ & $\begin{array}{l}43 \\
46 \\
48\end{array}$ & $\begin{array}{l}\text { Busy with matric }{ }^{10} \\
\text { (cleaners) }\end{array}$ & $\begin{array}{l}\text { English, } \\
\text { isiXhosa } \\
\text { English, } \\
\text { isiXhosa, } \\
\text { Afrikaans } \\
\text { English, } \\
\text { isiXhosa, } \\
\text { Afrikaans }\end{array}$ & $\begin{array}{l}\text { Six-week } \\
\text { relevant } \\
\text { training }\end{array}$ \\
\hline
\end{tabular}

\section{Comprehension test}

The interpreters were also tested on their comprehension of the English source texts, since all of them offered English and since the source text documents would have been explained to them in English. The translations into Afrikaans and isiXhosa were very close linguistic translations of the original, so if the interpreters did not understand the source text, they would not understand the target text either. Questions were also put on textual issues such as sentence and paragraph length, paragraph coherence, and stylistic and lexical suitability (Table 2).

Question 1 addresses the ideational clarity and no interpreter completely agreed that they clearly understood the message of the senders. Linguistic acceptability and terminological accuracy are addressed by questions 5 and 6 . Here no one agreed that the vocabulary and style of these texts were appropriate for the situation. Other remarks on the texts were that they found the texts too long to explain, but they did not think they themselves would be able to paraphrase the texts in order to shorten the time with the patients. Only one, the male interpreter from GSH, felt that if he were given enough time to work with the texts, he would be able to explain the contents to the parents or volunteers. The other interpreters did not feel comfortable explaining the information of the texts so that the patients or their parents could come to an informed decision about whether they should sign the document or not. None of the interpreters wanted sign the agreement certifying that they explained the information of the trial adequately in the patient's mother tongue and that the patient understood what was explained.

\footnotetext{
${ }^{9}$ This is the highest level of secondary schooling that can be obtained within the South African context. This gives access to tertiary education.

${ }^{10}$ It is a common tendency in South Africa that matured people further their studies or training as a way of improving their career prospects.
} 
Table 2: Responses to English source texts

\begin{tabular}{|c|c|c|c|c|c|}
\hline No. & Question & $\begin{array}{l}1 \text { - Don't agree at } \\
\text { all }\end{array}$ & 2 - Don't agree & 3-Agree & $\begin{array}{l}4-\text { Completely } \\
\text { agree }\end{array}$ \\
\hline 1 & 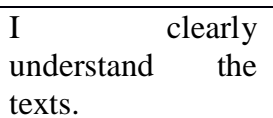 & $\begin{array}{l}\text { GSH } 1 \\
\text { TBH } 1\end{array}$ & $\begin{array}{l}\text { RXH } 1 \\
\text { GSH } 2\end{array}$ & RXH 1 & \\
\hline 2 & $\begin{array}{l}\text { The length of the } \\
\text { sentences is good. }\end{array}$ & $\begin{array}{l}\text { GSH } 1 \\
\text { TBH } 1\end{array}$ & RXH 2 & GSH 2 & \\
\hline 3 & $\begin{array}{l}\text { The paragraphs } \\
\text { are coherent. }\end{array}$ & & RXH 1 & $\begin{array}{l}\text { RXH } 1 \\
\text { GSH } 3 \\
\text { TBH } 1\end{array}$ & \\
\hline 4 & $\begin{array}{l}\text { The length of the } \\
\text { paragraphs is } \\
\text { good. }\end{array}$ & & & $\begin{array}{l}\text { RXH } 1 \\
\text { GSH } 3 \\
\text { TBH } 1\end{array}$ & RXH 1 \\
\hline 5 & $\begin{array}{l}\text { The vocabulary is } \\
\text { appropriate. }\end{array}$ & GSH 2 & $\begin{array}{l}\text { RXH } 2 \\
\text { GSH } 1 \\
\text { TBH } 1\end{array}$ & & \\
\hline 6 & $\begin{array}{l}\text { The style of the } \\
\text { text is appropriate. }\end{array}$ & GSH 3 & $\begin{array}{l}\text { RXH } 2 \\
\text { TBH } 1\end{array}$ & & \\
\hline
\end{tabular}

If these interpreters were to be confronted with this task, the ethical response would be to withdraw from the assignment unless they are supplied with a much simpler document or, preferably, have a healthcare provider with them doing the actual explanation. They could then revert to their primary role of interpreting as part of a trialogue (i.e., a dialogue or meeting between three people). The National Council on Interpreting in Healthcare (NCICH) (2004:16) also makes the point that " $[\mathrm{t}] \mathrm{o}$ work within the professional boundaries of the interpreter role also means that interpreters are aware of the limitations of their duties as well as the limitations of their abilities as a health care interpreter".

This behaviour of shifting the responsibility to the interpreter, as discussed above, and to put pen to paper regarding the effectiveness of the message was never intended but is an unintended observable effect of the availability of the interpreters. This in itself could hamper the initial intended effect of quality healthcare and borders on unethical behaviour.

\section{Discussion}

Regardless of the role of the interpreter, either as system or community agent, the basic goal of medical discourse is mutual understanding. Clear verbal communication is a necessary component of an effective clinical encounter. Even when patients and providers are educated in the same language, faulty communication can lead to distortions and miscommunications between the parties, let alone among educated healthcare providers, uneducated patients and semi-educated interpreters (Kaufert and Putsch, 1997 cited in Angelelli, 2004:18). Communicative failure as an unintended effect will inevitably be the result here, since neither interpreters nor parents ${ }^{11}$ or volunteers have the same level of literacy or knowledge as the compilers of the source texts. The parents or volunteers would therefore not be able to make informed decisions about agreeing to take part in the research project or not.

What is equally disturbing is that the interpreters are set up for failure when they are confronted with a task of this scope and these types of documents that they basically cannot understand. As gathered from the responses to the comprehension texts, these target texts will not be comprehensible enough to be viewed as providing an effective service to the client. According to Gile (1995:79-80), one is not able to fully comprehend something simply on the grounds of knowledge of the language or extralinguistic knowledge. The content of the speech may be too difficult, it may deviate from generally accepted linguistic standards, or the level of knowledge of the language and extralinguistic knowledge of the receiver may not be sufficient. It is then necessary to analyse the discourse itself to a much greater extent than one would analyse discourse with regard to comprehension in everyday situations. Therefore, to fully comprehend a text, one does not only need knowledge of the language and extralinguistic knowledge, but the discourse also requires purposeful analysis. This type of analysis could not be performed by most of the healthcare interpreters in South Africa and should rather be left to the healthcare providers or to adequately trained interpreters working with the healthcare providers in rendering a much simpler target text. However, where medical jargon hampering effective communication is not limited to South Africa (see Montalt and Garcia-Izquiedo, 2016).

\footnotetext{
${ }^{11}$ In the case of parents accompanying the children at RXH. See again section four. 
Further research that could flow from this could be competency testing of the interpreters to see how well they actually understand the information which had been communicated by the healthcare provider. In addition, after the interpreters have explained the information to the patients, the same competency testing could be done on the patients' understanding. The level of competency can be established by asking patients probing questions and inviting them to repeat the information they have received. Another way of addressing the issue at hand is to undertake a retranslation of the source texts into Afrikaans and into isiXhosa using the functionalist approach or a genre-specific community translation approach (De Klerk, et al., 2019; Lesch, 2018; Taibi and Ozolins, 2016:1-6). The interpreters could then be retested to see whether they then understand the target texts better and whether they would then be able to paraphrase and explain the content better to the patient. Keeping in mind the socio-economic and educational level of the prototypical patient for whom these informed consent forms are intended, I would still dissuade the interpreters from attempting to convey the message without a healthcare provider present and from signing the document as requested by the medical practitioner.

\section{Conclusion}

What the data shows us is that the intended effect of making interpreters available or installing an interpreting service was a noble one. It is envisaged to have a desirable effect on the quality of healthcare from a patient-centred perspective. In general, the availability of an interpreting service rightfully resulted in this. However, it has also resulted in unintended and undesirable effects. These unintended effects are not unique to the South African context. This is evident in Clifford's (2014) study on healthcare interpreting in Canada.

As discussed in this article, a major concern is the undesirable effect that the responsibility of the medical professional was shifted to the ill-equipped interpreter for the task at hand as considered above and that the interpreter had to confirm it in writing. The question is whether it is ethical to leave the explaining to the interpreters and then expect that they should sign the informed consent forms, declaring that the content has been fully understood by the parents or volunteers? Obviously, the unintended effect could positively feed into the recruitment and training of interpreters. If this approach gains momentum in practice, it will also mean that enhanced training should be provided, and the role and responsibilities of the interpreter should be extended officially. Ultimately, this will contribute positively towards the clinical encounter.

\section{References}

Angelelli, C. (2004). Medical interpreting and cross-cultural communication. Cambridge: Cambridge University Press.

Antonini, R., Cirillo, L., Rossato, L., and Torresi, I. (2017). Non-professional Interpreting and Translation. State of the Art and Future of an Emerging Field of Research. Amsterdam/Philadelphia: John Benjamins.

Berlund, L.O. (1990). The search for social significance. Lebende Sprachen 35:4.145-151

Cape Gateway. (2009). Groote Schuur Hospital: Fast facts as at November 2007 [Electronic]. Available: http://www.capegateway.gov.za/other/2008/4/fast_facts_gsh_nov07.pdf. [2009, October 26].

Census (2011) Provincial Profile: Western Cape Report http://www.statssa.gov.za/publications/Report-03-0170/Report-03-01-702011.pdf

Chesterman, A. (1998). Causes, Translations, Effects. Target, 10(2):201-23.

Chesterman, A. (2000). A causal model for translation studies. In M. Olohan (ed.), Intercultural Fault lines. Research in Model in Translation Studies. Textual and Cognitive Aspects. Manchester: St. Jerome Publishing. 15-27.

Clifford, A. (2014) Interpreting Effects: From Legislative Framework to End-Users. In Mezei et al. (eds.), Translation Effects. The Shaping of Modern Canadian culture. Montreal and Kinston: McGill-Queen's University Press. 416-429.

Cole, P., Lawrence, L., Nyubuse, N and Godden, J. (2003). Costing the Western Cape language policy. Cape Town: Emzantsi Associates,.

De Klerk, S., Jerosch-Herold, C., Buchanan, H. and Van Niekerk, L. (2019) Shared decision making and the practice of community translation in presenting a pre-final Afrikaans for the Western Cape Disabilities of the Arm, Shoulder and Hand (DASH) questionnaire: a Proposal for improved translation and cross-cultural adaptation. Journal of Patient-Reported Outcomes,3:52.

Feinauer, I. and Lesch, H. (2013). Health workers: idealistic expectations versus interpreters' competence. Perspectives: Studies in Translatology, 21(1):117-132.

Fourth International Conference on Non-Professional Interpreting and Translation (NPIT4) 2018. Call for Papers leaflet, Stellenbosch Institute for Advanced Study (STIAS), Stellenbosch University, South Africa.

Gile, D. (1995). Basic concepts and models for interpreter and translator training. Amsterdam: John Benjamins.

Johnstone, M. (1999). Bioethics. A nursing perspective. Sydney: Harcourt.

Lesch, H. (2018). From practice to theory: Societal factors as norm governing principle for community Translation. In M. Taibi (ed.), Translating for the community. Bristol and Blue Ridge Summit: Multilingual Matters. 
Lesch, H. and Saulse, B. (2014). Revisiting the Interpreting Service in the Healthcare sector: a

Descriptive overview. Perspectives: Studies in Translatology, 22(3):332-348.

Montalt, V. and Garcia-Izquierdo, I. (2016). Exploring the links Between the Oral and the Written in PatientDoctor Communication. In P. Ordonez-Lopez and N. Edo-Marza (eds.), Medical Discourse in Professional, Academic and Popular Settings. Bristol: Multilingual Matters

Mezei, K., Simon, S. and Von Flotow, L. (2014). Translation Effects. The Shaping of Modern Canadian culture. Montreal and Kinston: McGill-Queen's University Press.

NCICH. (2004). A national code of ethics for interpreters in health care, in The National Council on Interpreting in Health Care: Working Papers Series [Electronic]. Available: http://www.nchic.org [2017, August 30].

Nida, E. A. (1964). Toward a science of translating. Leiden: E. J. Brill.

Nord, C. 2005. Text analysis in Translation. Theory, Methodology and Didactic Application of a Model for Translation-Oriented text analysis. Translated from German by Nord, C. \& P. Sparrow, Amsterdam: Rodopi

Pym, A. (1992). The relation between Translation and Material Text Transfer. Target, 4:2:171-189.

Saulse, B. (2010). Interpreting within the Western Cape Health Care Sector: A Descriptive Overview. Unpublished master's thesis. Stellenbosch: Stellenbosch University.

Schlemmer, A.C. (2005). Exploring the Effects of a Language Barrier between the Patients and Staff at Hottentots Holland Hospital. Unpublished research assignment. Stellenbosch: Stellenbosch University.

Shuttleworth, M. and Cowie, M. (1997). Dictionary of Translation Studies. Manchester: St. Jerome Publishing.

Taibi, M. and Ozolins, M. (2016) Community Translation. London: Bloomsbury.

Toury, G. (1995). Descriptive translation studies and beyond. Amsterdam: John Benjamins.

Internet sites visited:

https://www.westerncape.gov.za/assets/departments/health/tygerberg_hospital_information_pamphlet_-_2016.pdf (visited 26 June 2019)

https://www.childrenshospitaltrust.org.za/wp-content/uploads/2019/07/The-Childrens-Hospital-Trust-AnnualReport-2018.pdf (visited 26 June 2019)

https://www.gshfb.co.za/wp-content/uploads/2017/11/fast-facts-2017.pdf (visited 26 June 2019) 